\title{
Silicon surface texturing for enhanced nanocrystalline diamond seeding efficiency
}

\author{
Jong Cheon Park, Ok Geun Jeong, Sang Youn Kim, Se Jin Park*, Young-Hoon Yun** and Hyun Cho*, \\ Department of Nano Fusion Technology, Pusan National University, Miryang 627-706, Korea \\ *Department of Nanomechatronics Engineering, Pusan National University, Miryang 627-706, Korea \\ **Department of Hydrogen \& Fuel Cell Technology, Dongshin University, Naju 520-714, Korea
}

(Received March 4, 2013)

(Revised April 3, 2013)

(Accepted April 12, 2013)

Abstract $\mathrm{SF}_{6} / \mathrm{O}_{2}$ inductively coupled plasmas were employed to texture $\mathrm{Si}$ surface as a pretreatment for nanocrystalline diamond film growth. It was found that the $\mathrm{SF}_{6} / \mathrm{O}_{2}$ plasma texturing provided a very wide process window where normalized roughness values in the range of $2 \sim 16$ could be obtained. Significantly improved nucleation densities of $\sim 6.5 \times 10^{10} \mathrm{~cm}^{-2}$ compared to conventional mechanical abrasion were achieved after seeding for the textured Si substrate.

Key words Nanocrystalline diamond seeding, Si surface texturing, Fluorine-based plasma, Surface roughness, Nucleation density

\section{나노결정질 다이아몬드 seeding 효율 향상을 위한 silicon 표면 texturing}

\author{
박종천, 정옥근, 김상윤, 박세진*, 윤영훈**, 조현*, \\ 부산대학교 나노융합기술학과, 밀양, 627-706 \\ *부산대학교 나노메카트로닉스공학과, 밀양, 627-706 \\ **동신대학교 수소에너지학과, 나주, 520-714 \\ (2013년 3월 4일 접수) \\ (2013년 4월 3일 심사완료) \\ (2013년 4월 12일 게재확정)
}

요 약 나노결정질 다이아몬드 박막 증착을 위한 전처리 공정으로 $\mathrm{SF}_{6} / \mathrm{O}_{2}$ 유도결합 플라즈마를 이용하여 $\mathrm{Si}$ 기판 표면 을 texturing하였다. $\mathrm{SF}_{6} / \mathrm{O}_{2}$ 플라즈마 texturing은 2 16 범위의 매우 넓은 정규화된 표면 조도 선택성을 제공할 수 있음을 확 인하였다. Texturing된 $\mathrm{Si}$ 기판 표면의 나노 다이아몬드 입자 seeding 이후 기존 기계적 연마 전처리에 비해 현저히 향상된 $\sim 6.5 \times 10^{10} \mathrm{~cm}^{-2}$ 의 높은 핵형성 밀도를 확보하였다.

\section{1. 서 론}

최근에 개발된 나노결정질 다이아몬드(nanocrystalline diamond, NCD) 코팅은 매우 얇은 박막의 형태로부터 천연 다이아몬드의 고유한 특성을 구현하는 것이 가능하 기 때문에 많은 관심을 받고 있다. 나노결정질 다이아몬드 층은 증착과정에서 기존 마이크로미터 스케일의 결정질 다이아몬드층에 비해 더 높은 재핵생성율(re-nucleation

\footnotetext{
Corresponding author

Tel: +82-55-350-5286

Fax: +82-55-350-5289

E-mail: hyuncho@pusan.ac.kr
}

rate)이 확보되는 조건 하에서 성장된 다이아몬드층으로서 5-30 나노미터 정도의 평균 입자크기를 가진다[1,2]. 나노 결정질 다이아몬드 박막은 우수한 기계적, 열적, 전기적 및 화학적 특성을 가져 기계식 펌프 밀봉재(mechanical pump seals)나 공구용 초저마찰/마모 코팅, 초미세전기기 계결합소자(MEMS/NEMS), 고해상도 평판 디스플레이, 생체용 바이오 소자 및 바이오 센서 등 다양한 분야에 응용 가능한 것으로 알려져 있다[3-6].

대부분의 나노결정질 다이아몬드 박막 응용에 있어서 가장 중요한 인자는 낮은 표면 조도를(surface roughness) 가지는 평탄한 표면 특성을 확보하는 것이며, 표면 조도 에 직접적인 영향을 미치는 것은 초기 핵생성을 위한 표 
면 전처리 공정이다[7]. 전처리 공정의 목적은 증착 초 기 단계에 나노 다이아몬드 핵이 생성 또는 성장될 수 있는 자리를 만들기 위해 표면을 일정 수준의 조도로 거 칠게 가공하는 것이다. 기존 마이크로미터 스케일의 결 정질 다이아몬드 박막 증착에서 많이 사용된 전처리 공 정으로는 수 마이크로미터 크기의 다이아몬드 입자를 이 용한 기계적 연마(mechanical abrasion or scratching) 또는 micro-chipping, bias-enhanced nucleation(BEN), 탄화처리(carburization) 등이 있다[8-11].

기판 표면을 기계적으로 연마할 경우, 수 마이크로미 터 깊이의 흠집(scratch)을 표면에 형성하게 되는데, 전 처리 이후 후속적으로 진행되는 나노 다이아몬드 입자 seeding과정에서 seed 입자들이 이 흠집들 속에 불균일 하게 함몰되어 균일한 핵생성 밀도를 확보하는 것이 용 이하지 않다. 또한, 전처리된 표면 조도 특성이 증착된 박막으로 복사되는(replication) 현상이 발생하게 되어 평 탄한 표면 특성을 가지는 나노결정질 다이아몬드 박막 증착에는 적절치 않다. $\mathrm{BEN}$ 공정은 그 특성상 기판이 전기전도성을 가져야 하고 기판 표면에 높은 바이어스를 인가해야 하므로 표면에 부가적인 손상(damage)을 유발 할 가능성이 있고, 탄화처리는 표면에 일정 두께의 탄화 층 형성이 필수적이기 때문에 얇은 두께의 나노다이아몬 드 박막 형성을 필요로 할 경우에는 부적절하다 $[12,13]$. 따라서, 평탄한 표면 특성을 갖는 나노결정질 다이아몬 드 박막을 증착하기 위해서는 기판 표면을 나노미터 스 케일의 조도로 균일하게 가공함으로써 높은 seeding 효 율을 확보할 수 있는 전처리 기술 개발이 매우 중요하다. 본 연구에서는 $\mathrm{Si}$ 기판에 평탄한 나노결정질 다이아몬드 박막 증착을 위한 전처리 공정으로 기존 반도체 공정에 서 폭넓게 활용되고 있는 fluorine-계 유도결합 플라즈마 식각 기술을 적용하여 $\mathrm{Si}$ 기판 표면을 texturing하였다. 가스 유량, 인가 power, 압력 등의 공정 변수가 $\mathrm{Si}$ 식각 속도와 texturing된 표면 특성에 미치는 영향, 플라즈마 texturing이 나노다이아몬드 핵형성 밀도에 미치는 영향 등을 조사하였다.

\section{2. 실험과정}

본 연구에서는 p-형 (100) Silicon 단결정 wafer를 기 판으로 사용하였다. 먼저 $\mathrm{Si}$ wafer 표면에 존재하는 오 염물 입자들을 제거하기 위하여 $\mathrm{HF}$ 희석용액 중에서 1 분 동안 초음파 세척한 후, 아세톤, DI water bath에서 각각 5 분 동안의 초음파 세척을 통해 세정과정을 진행 하였다. 세정된 $\mathrm{Si}$ 시편을 planar type 유도결합 플라즈 마(inductively coupled plasma, ICP) 식각장치에 장입한 후 $\mathrm{CF}_{4} / \mathrm{O}_{2}, \mathrm{SF}_{6} / \mathrm{O}_{2}$ 플라즈마를 이용하여 surface texturing
하였다. $\mathrm{CF}_{4}, \mathrm{SF}_{6}$ 가스와 산소 가스의 유량비율은 2-4:1, 총 유량은 27 50 sccm으로 유지하였고, ICP power는 $100 \sim 800 \mathrm{~W}, \mathrm{rf}$ power는 100 250 W, 공정 압력은 10 $70 \mathrm{mTorr}$ 범위에서 변화시킨 다양한 조건들을 적용하였 다. 또한, 각각의 surface texturing 조건에서의 $\mathrm{Si}$ 의 식 각 속도를 측정하기 위하여 photoresist( $\mathrm{PR}$ ) mask 층을 형성하였다. Surface texturing 공정 이후 표면 양상과 표면 조도는(surface roughness) atomic force microscopy (AFM, PSIA SE100), 식각 속도는 stylus profilometry 장비를 이용하여 분석하였다. Surface texturing이 완료 된 $\mathrm{Si}$ 시편을 $3 \sim 5 \mathrm{~nm}$ 크기를 갖는 나노결정질 다이아몬 드 입자가 균일하게 분산된 에탄올 초음파 bath에 담근 후 30 분 동안 seeding 공정을 진행하였다. Seeding 후 시편을 DI water 초음파 bath에 침지하여 각 1 분씩, 3 회 세척 과정을 진행하였다. 건조 과정 이후 field-emission scanning electron microscopy(FE-SEM, Hitachi S4700) 를 이용한 표면 분석을 통해 나노결정질 다이아몬드 핵 형성 밀도를 조사하였다.

\section{3. 결과 및 고찰}

Fig. 1 에 $40 \mathrm{SF}_{6} / 10 \mathrm{O}_{2}$ 플라즈마에서 ICP source power 와 압력을 각각 $800 \mathrm{~W}, 70 \mathrm{mTorr}$ 로 고정한 상태에서 $\mathrm{rf}$ chuck power를 $100,150,200,250 \mathrm{~W}$ 로 변화시키면서 surface texturing한 $\mathrm{Si}$ 시편의 표면 특성을 $\mathrm{AFM}$ 으로 분 석한 결과를 나타내었다. Rf power $150 \mathrm{~W}$ 조건을 제외 하면, 전반적으로 $\mathrm{rf}$ chuck power가 증가함에 따라 texturing된 표면의 조도가 증가하는 경향을 나타냄을 알 수 있다. 일반적인 플라즈마 공정에서 시편 표면 원자의 제거 속도는 플라즈마 내에 존재하는 이온의 밀도와 평 균 이온 에너지의 직접적인 영향을 받게 되는데, 이중 평균 이온 에너지는 rf chuck power에 의해 제어된다. 즉, $\mathrm{rf}$ power가 증가함에 따라 플라즈마 내에 존재하는 이온들이 가지는 평균 에너지는 증가하게 되고, 시편 표 면에 대한 이들 이온들의 포격효과(ion bombardments) 는 더 활성화되어 제거 속도는 증가할 것이다. 이에 반 해, 시편 표면 전 영역에 걸친 원자 제거 속도의 균일성 은 감소하였기 때문에 $\mathrm{Si}$ 의 표면 조도가 증가하는 것으 로 해석할 수 있다.

Fig. 2에 Fig. 1에 제시된 조건들 하에서 측정된 $\mathrm{Si}$ 의 식 각 속도를 제시하였다. Rf power 증가로 인해 플라즈마 식각의 물리적 요소인 이온 포격이 활성화됨에 따라 $\mathrm{Si}$ 식각 속도가 계속적으로 증가하는 경향을 나타내고, 최고 약 $8600 \AA / \mathrm{min}$ 의 매우 높은 식각 속도가 얻어졌다. 또한, 이 조건들 하에서 texturing된 $\mathrm{Si}$ 표면의 조도는 texturing 하지 않은 control 시편에(root-mean-square roughness 


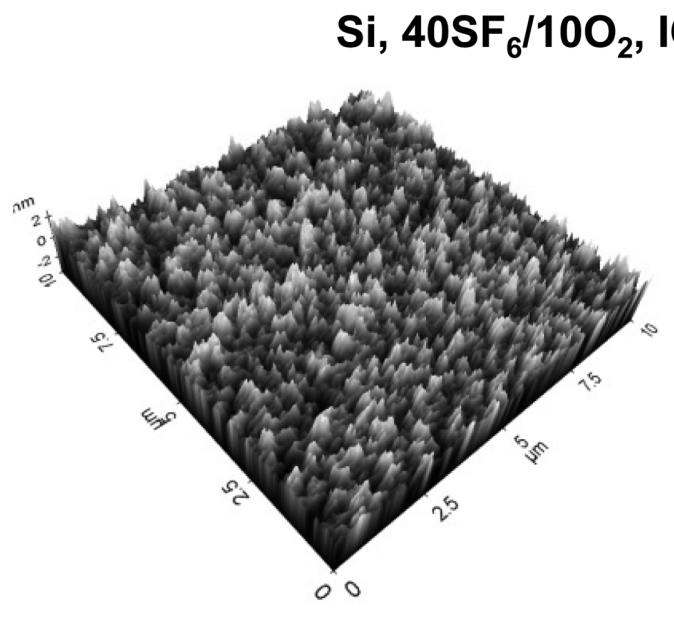

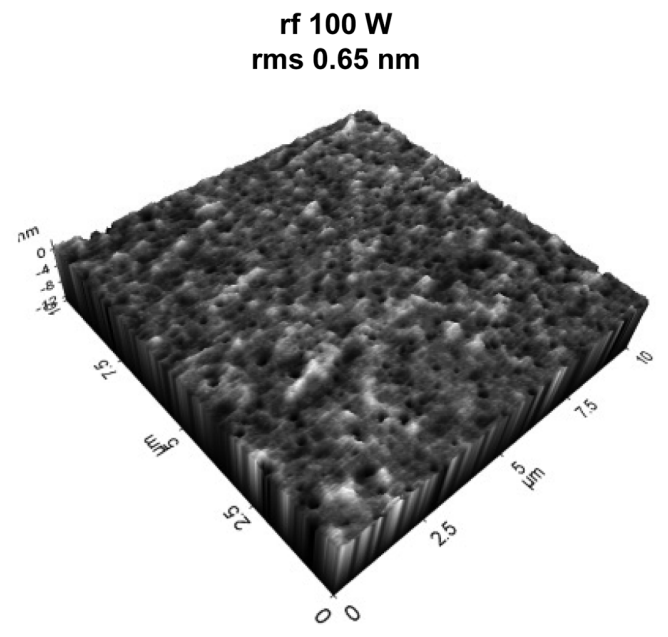

rf $200 \mathrm{~W}$
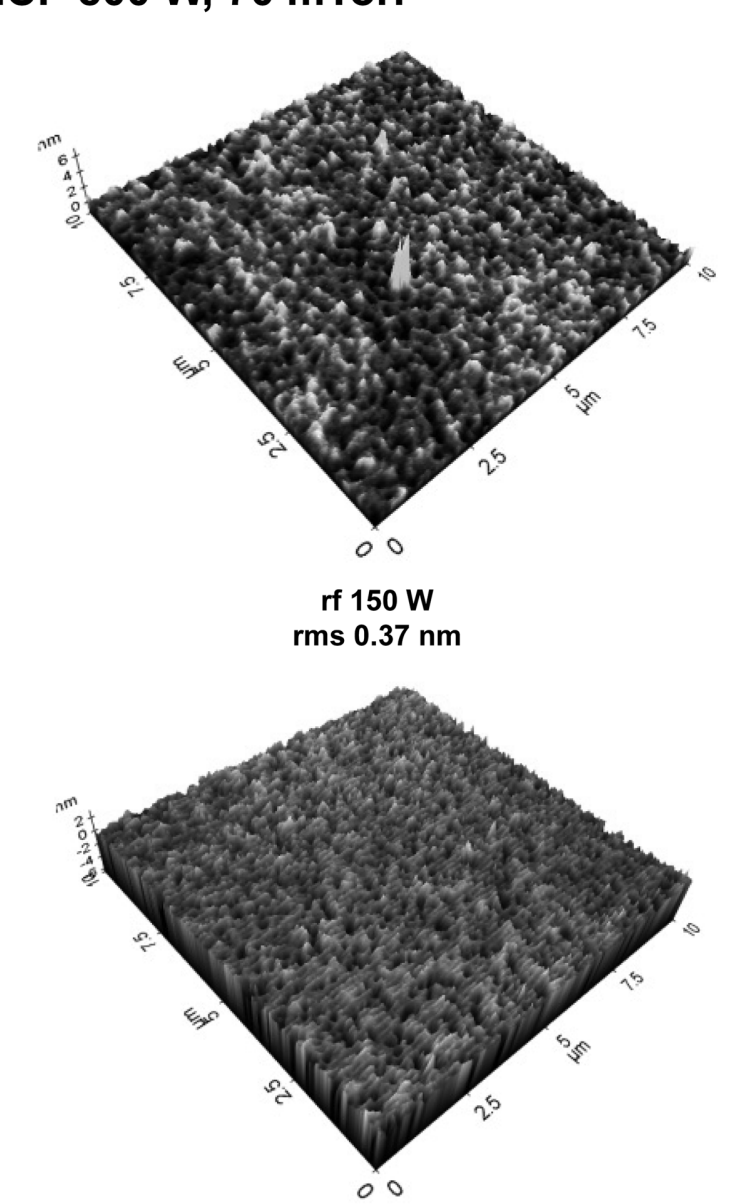

rf $250 \mathrm{~W}$ rms $0.93 \mathrm{~nm}$

Fig. 1. AFM scan images of $\mathrm{Si}$ textured with variation of $\mathrm{rf}$ chuck power in $40 \mathrm{SF}_{6} / 10 \mathrm{O}_{2}$ ICP discharges $(800 \mathrm{~W}$ source power, 70 mTorr)
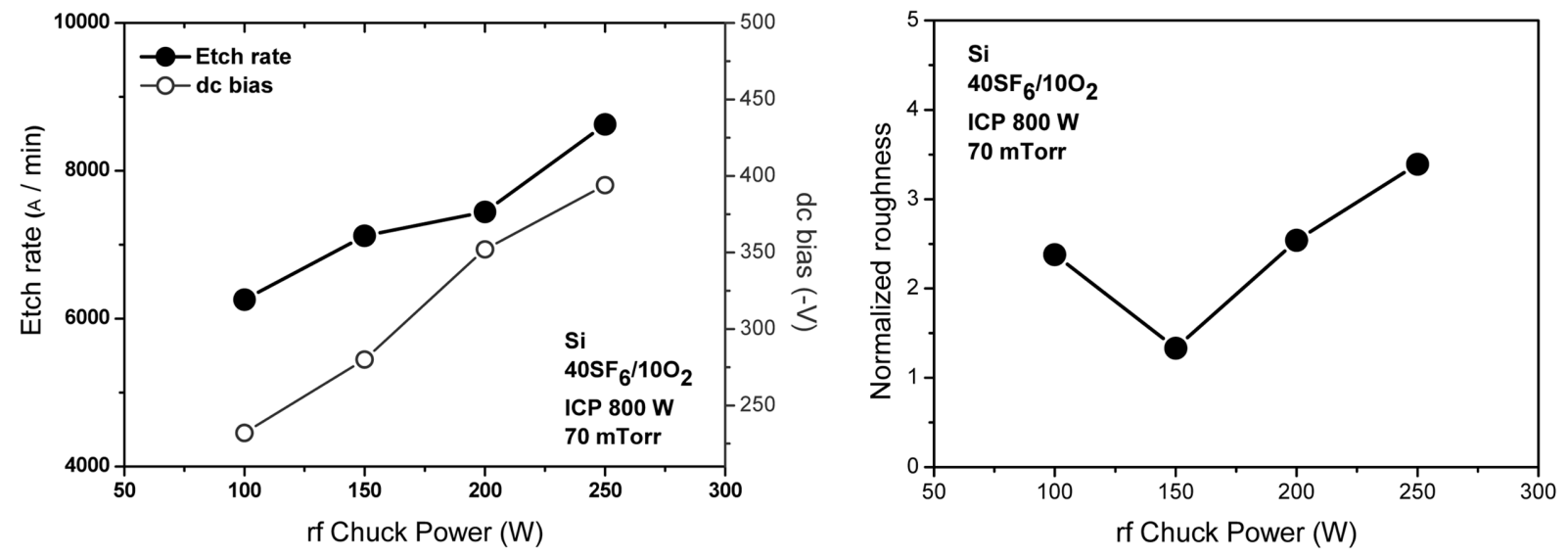

Fig. 2. Dependence of $\mathrm{Si}$ etch rate and normalized textured surface roughness on rf chuck power in $40 \mathrm{SF}_{6} / 10 \mathrm{O}_{2}$ ICP discharges ( $800 \mathrm{~W}$ source power, $70 \mathrm{mTorr}$ ).

$0.27 \mathrm{~nm}$ ) 비해 1.3 3.4 범위의 정규화된 조도(normalized roughness) 값들을 나타내었다.

Fig. 3은 Fig. 1에 제시한 것과 동일한 조건을 유지한
상태에서 플라즈마 조성만을 $40 \mathrm{CF}_{4} / 10 \mathrm{O}_{2}$ 로 변경한 환경 하에서 texturing한 $\mathrm{Si}$ 시편의 표면 양상을 $\mathrm{AFM}$ 으로 분 석한 결과를 보여주고 있다. $40 \mathrm{SF}_{6} / 10 \mathrm{O}_{2}$ 플라즈마와 달 


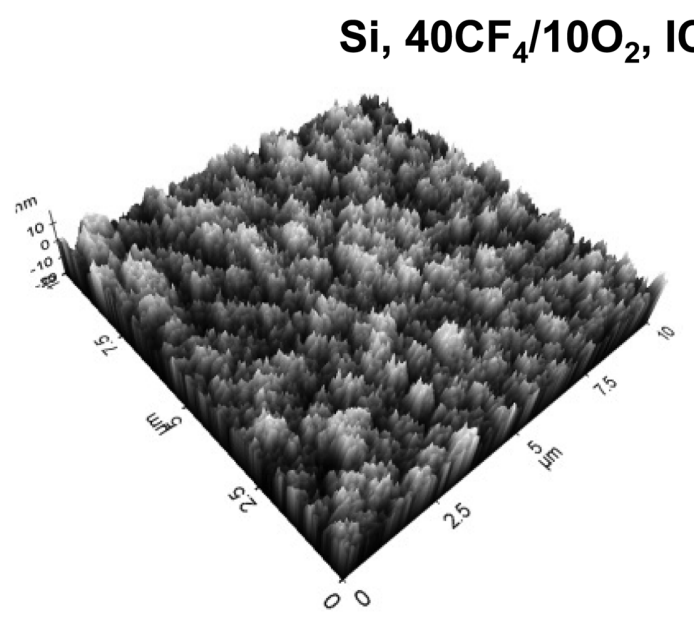

, ICP 800 W, 70 mTorr
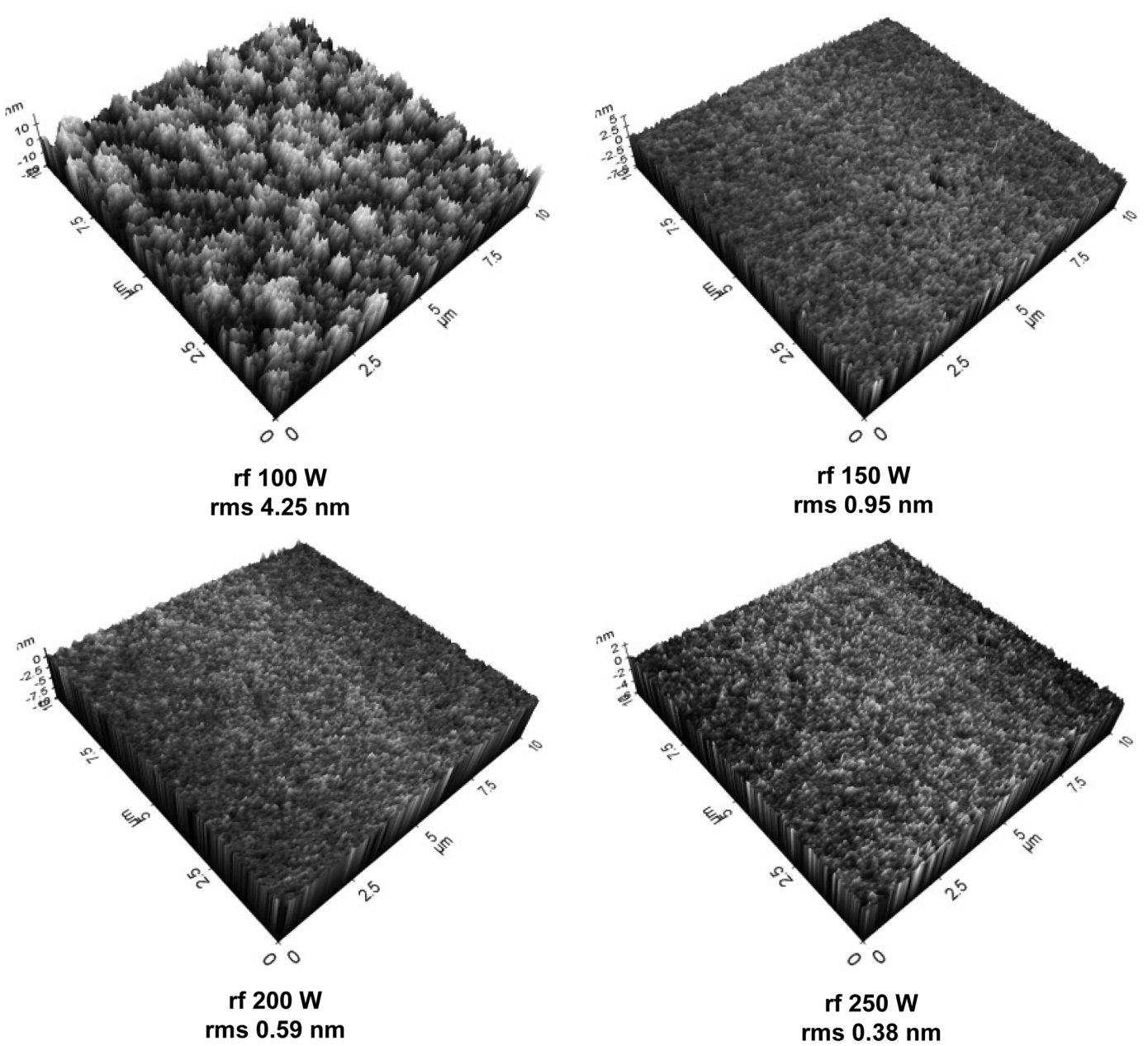

Fig. 3. AFM scan images of $\mathrm{Si}$ textured with variation of $\mathrm{rf}$ chuck power in $40 \mathrm{CF}_{4} / 10 \mathrm{O}_{2}$ ICP discharges ( $800 \mathrm{~W}$ source power, 70 mTorr).
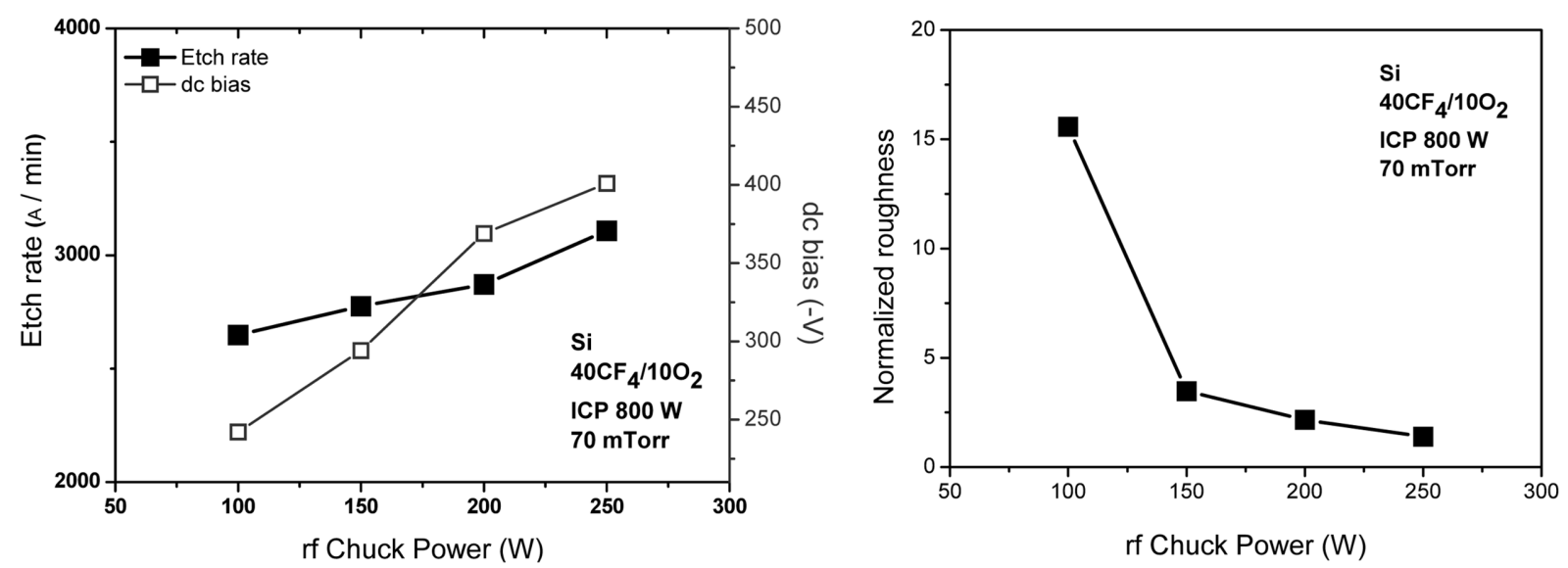

Fig. 4. Dependence of $\mathrm{Si}$ etch rate and normalized textured surface roughness on rf chuck power in $40 \mathrm{CF}_{4} / 10 \mathrm{O}_{2} \mathrm{ICP}$ discharges ( $800 \mathrm{~W}$ source power, $70 \mathrm{mTorr}$ ).

리 $40 \mathrm{CF}_{4} / 10 \mathrm{O}_{2}$ 플라즈마에서는 $\mathrm{rf}$ chuck power가 증가 함에 따라 표면 조도가 지속적으로 감소하는 surface smoothing 현상이 관찰되었다. 이는 rf power가 증가함
에 따라 $\mathrm{Si}$ 표면에 대한 이온 포격 효과가 더 활성화되 었을 뿐만 아니라 전 표면 영역에 걸쳐 표면 원자들이 균일한 속도로 제거된 결과로 판단된다. 

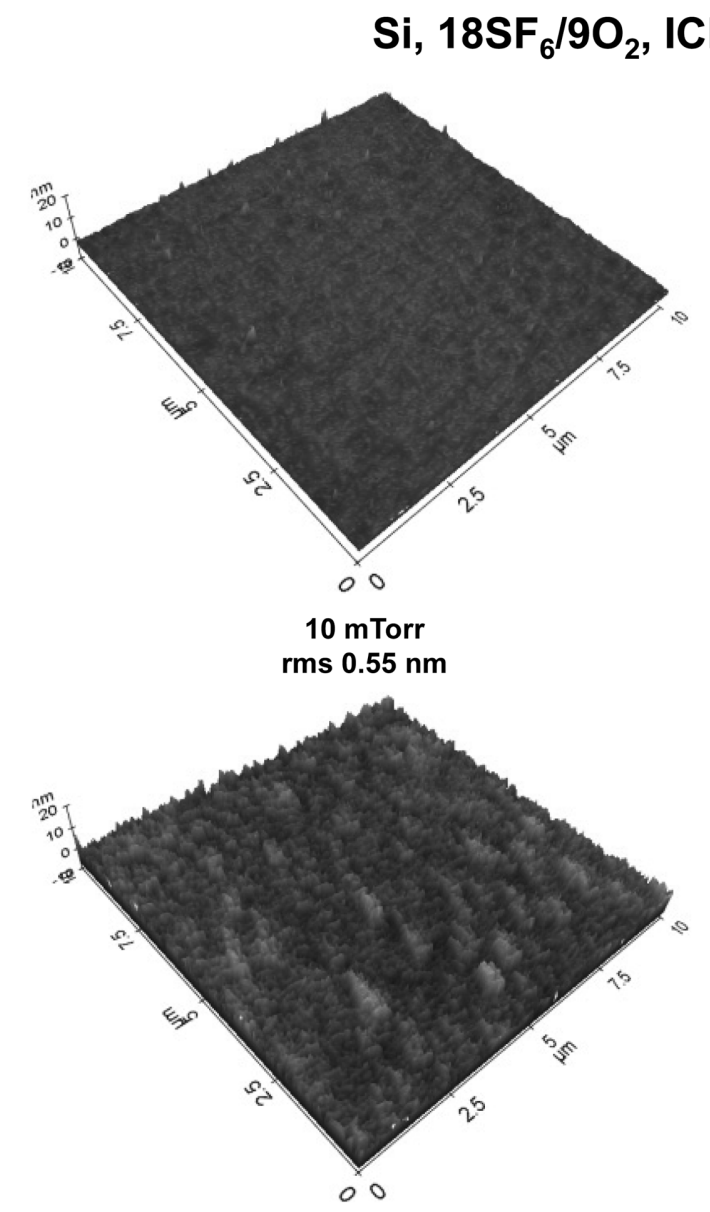

$50 \mathrm{mTorr}$
rms $2.36 \mathrm{~nm}$

\section{$400 \mathrm{~W}$, rf $100 \mathrm{~W}$}
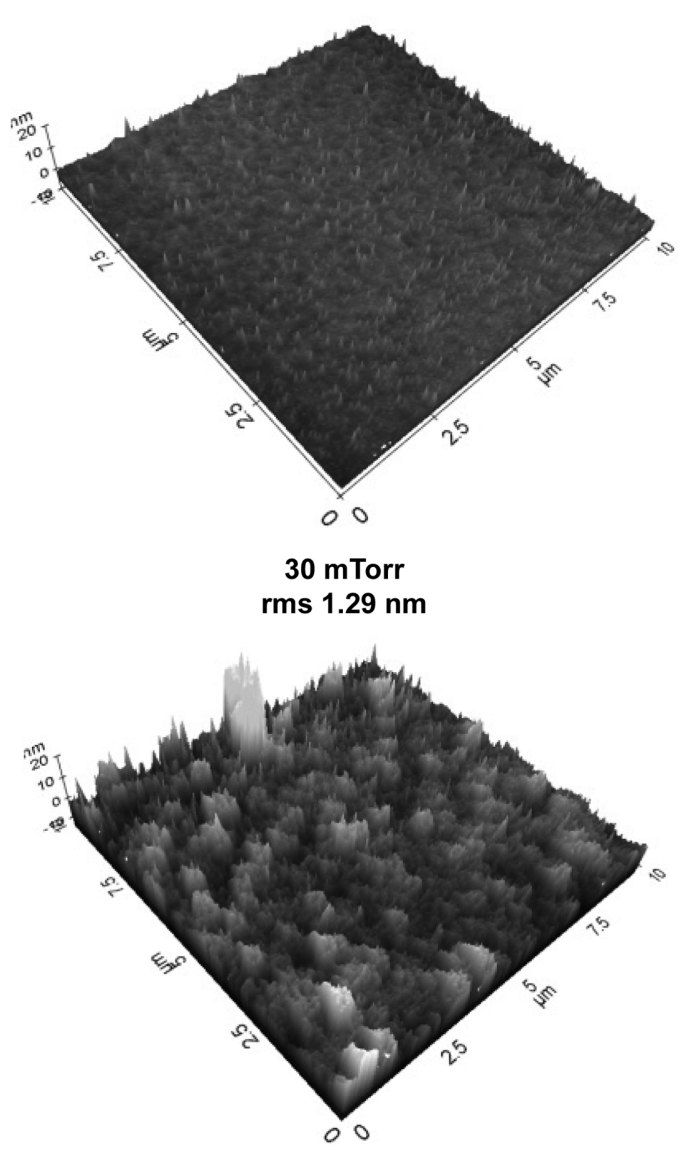

$70 \mathrm{mTorr}$

Fig. 5. AFM scan images of $\mathrm{Si}$ textured with variation of process pressure in $18 \mathrm{SF}_{6} / 9 \mathrm{O}_{2} \mathrm{ICP}$ discharges ( $400 \mathrm{~W}$ source power, $100 \mathrm{~W}$ rf chuck power).

$40 \mathrm{CF}_{4} / 10 \mathrm{O}_{2}$ 플라즈마에서 $\mathrm{rf}$ power 증가에 따른 $\mathrm{Si}$ 식각 속도 및 normalized roughness 변화를 Fig. 4에 제 시하였다. $40 \mathrm{SF}_{6} / 10 \mathrm{O}_{2}$ 플라즈마에서 관찰된 결과와(Fig. 2) 마찬가지로 rf power가 증가함에 따라 $\mathrm{Si}$ 식각 속도 가 계속적으로 증가하는 동일한 경향성을 나타내었으나, 식각 속도가 $2650 \sim 3108 \AA / \mathrm{min}$ 으로 $40 \mathrm{SF}_{6} / 10 \mathrm{O}_{2}$ 플라즈 마에 비해 현저히 낮은 값들이 측정되었다. 이러한 차이 는 두 불소계 식각 가스의 평균 분자 결합 에너지 차이 에서 기인한 것으로 이해된다. $\mathrm{SF}_{6}$ 가스의 평균 분자 결합 에너지는 $284 \mathrm{~kJ} / \mathrm{mol}$ 인데 반해 $\mathrm{CF}_{4}$ 가스는 $485 \mathrm{~kJ} / \mathrm{mol}$ 로 더 높은 값을 가지는데, 이는 동일한 power 조건 하 에서 $\mathrm{SF}_{6}$ 가스가 $\mathrm{CF}_{4}$ 에 비해 $\mathrm{Si}$ 표면 원자와 반응하여 식각 생성물을 형성할 수 있는 더 높은 밀도의 fluorine radical을 공급해 줄 수 있기 때문에 더 높은 식각 속도 확보가 가능한 것으로 생각된다. $40 \mathrm{CF}_{4} / 10 \mathrm{O}_{2}$ 플라즈마 에서 $\mathrm{rf}$ power가 증가함에 따라 16 1.4 범위의 정규화 된 조도값들이 얻어졌다.

플라즈마를 이용한 $\mathrm{Si}$ wafer 표면 texturing은 그 특성
상 일반적인 플라즈마 식각과는 달리 표면의 식각 속도 는 가급적 낮은 영역에서 폭넓은 표면 조도 선택성을 가 지는 것이 요구된다. Fig. 1 4에서 제시한 결과들은 상 대적으로 식각 속도가 높고 표면 조도의 선택성 또한 제 한적인 것으로 판단되어 식각 가스의 총유량과 인가 power를 낮은 영역으로 변경한 조건 하에서 $\mathrm{Si}$ 표면 texturing을 수행하고 그 특성을 평가하였다. Fig. 5는 $18 \mathrm{SF}_{6} / 9 \mathrm{O}_{2}$ 가스 조성, ICP source power $400 \mathrm{~W}$, rf chuck power $100 \mathrm{~W}$ 조건에서 공정 압력을 10 70 mTorr로 변 경한 조건에서 texturing한 $\mathrm{Si}$ 시편의 $\mathrm{AFM}$ 분석 결과이 다. 그림에서 보는 바와 같이 공정 압력이 증가함에 따 라 texturing된 $\mathrm{Si}$ 표면의 조도가 증가함을 알 수 있다. 공정 압력 증가는 플라즈마 내에 존재하는 fluorine radical 밀도 증가를 유도하기 때문에 플라즈마와 $\mathrm{Si}$ 표 면과의 물리적 상호작용보다는 화학적 상호작용을 더 향 상시키게 된다. 플라즈마와 $\mathrm{Si}$ 표면 간의 화학적 상호작 용이 더 우세할 경우, 일반적으로 더 거친 표면 양상을 나타내게 된다. 

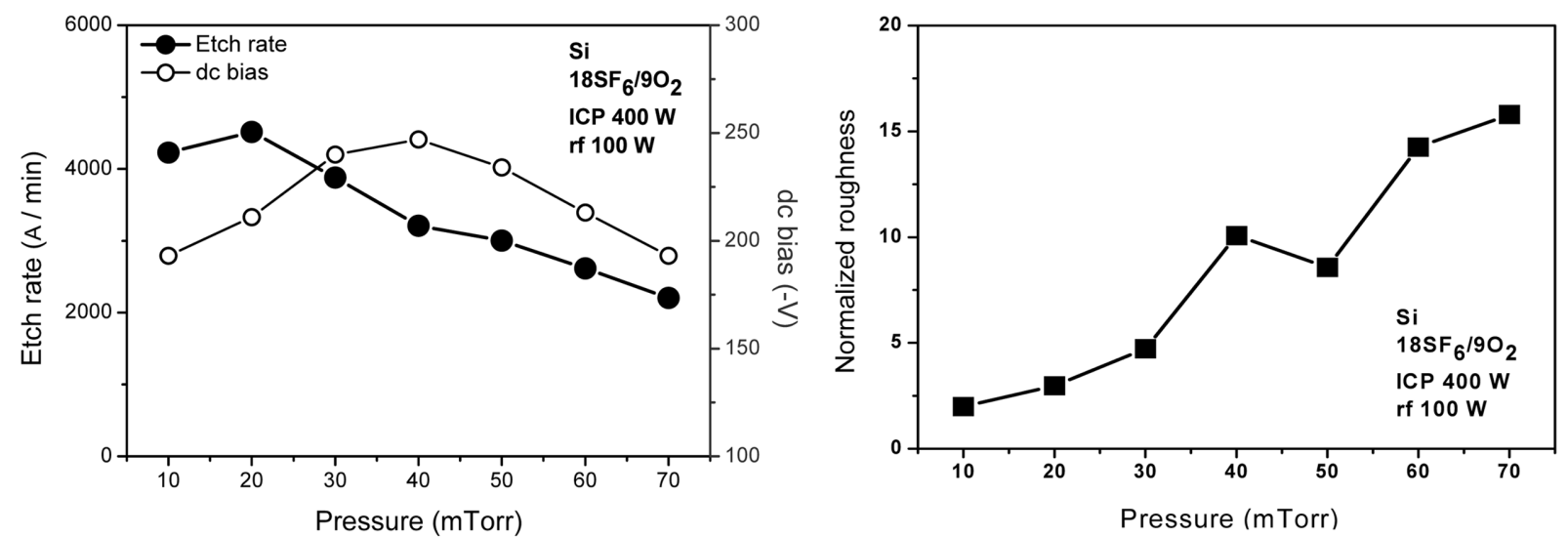

Fig. 6. Dependence of $\mathrm{Si}$ etch rate and normalized textured surface roughness on process pressure in $18 \mathrm{SF}_{6} / 9 \mathrm{O}_{2} \mathrm{ICP}$ discharges (400 W source power, $100 \mathrm{~W}$ rf chuck power).

Fig. 6에 도시한 바와 같이 공정 압력이 증가함에 따 라 $\mathrm{Si}$ 식각 속도는 감소하는 양상을 나타내었으며, 총 유량과 인가 power를 낮춤에 따라 Fig. 2에 제시한 결 과에 비해 더 낮은 영역의 식각 속도가(2200 4500 $\AA$ / $\mathrm{min}$ ) 측정되었다. 여기서 특히 주목할 사항은 2 16 범 위의 매우 넓은 영역의 정규화된 표면 조도 선택성이 확 보되었다는 것이다. 즉, 공정 압력 조정을 통해 texturing 이전의 $\mathrm{Si}$ 표면과 거의 비슷한 거칠기를 갖는 표면으로 부터 16 배 정도 거친 표면까지 다양하게 선택할 수 있 는 공정 조건을 확립하였다.

$18 \mathrm{SF}_{6} / 9 \mathrm{O}_{2}$, ICP source power $400 \mathrm{~W}$, rf chuck power $100 \mathrm{~W}, 10 \mathrm{mTorr}$ 유도결합 플라즈마를 이용하여 texturing 한 $\mathrm{Si}$ 표면(좌측) 및 texturing 이후 나노결정질 다이아 몬드 입자 분산액 중에서 seeding을 완료한 $\mathrm{Si}$ 표면을 (우측) SEM으로 관찰한 이미지를 Fig. 7에 비교하였다. Texturing 이전에 비해 표면 조도가 약 2 배 정도 증가하 였지만 특이한 형상물이 표면에서 관찰되지 않는 반면에, 나노결정질 다이아몬드 입자 seeding 이후에는 확연히 다른 표면 양상을 나타냄을 알 수 있다. Seeding된 나노 다이아몬드 입자들은 평균 $20 ~ 30 \mathrm{~nm}$ 크기의 응집체 형
태로 $\mathrm{Si}$ 시편의 전 영역에 걸쳐 매우 높은 밀도로 균일 하게 분포하고 있음을 알 수 있다. 고배율 SEM 사진의 육안 관찰을 통해 집계한 결과, $\sim 6.5 \times 10^{10} \mathrm{~cm}^{-2}$ 의 매우 높은 핵형성 밀도(nucleation density)가 얻어졌다. 이러 한 결과는 $10^{8} \sim 10^{9} \mathrm{~cm}^{-2}$ 범위의 핵형성 밀도를 확보하는 것이 일반적인 기존 기계적 연마 전처리에 비해 현저하 게 향상된 핵형성 밀도이다. 따라서, 본 연구에서 시도한 $\mathrm{SF}_{6} / \mathrm{O}_{2}$ 플라즈마 texturing이 $\mathrm{Si}$ 표면으로부터 높은 나노 다이아몬드 seeding 효율을 확보하는데 매우 효과적인 전처리 공정임을 확인하였다.

\section{4. 결 론}

평탄한 표면 특성을 가지는 나노결정질 다이아몬드 코 팅층 증착을 위하여 반도체 소자 제조공정에서 폭넓게 활용되는 플라즈마 식각 기술을 도입하여 $\mathrm{Si}$ 기판 표면 을 texturing하고 표면 특성을 조사하였다. 상대적으로 높은 가스 총유량과 인가 power 조건 하에서 형성된 $\mathrm{CF}_{4} / \mathrm{O}_{2}, \mathrm{SF}_{6} / \mathrm{O}_{2}$ 플라즈마를 이용하여 texturing한 $\mathrm{Si}$ 표
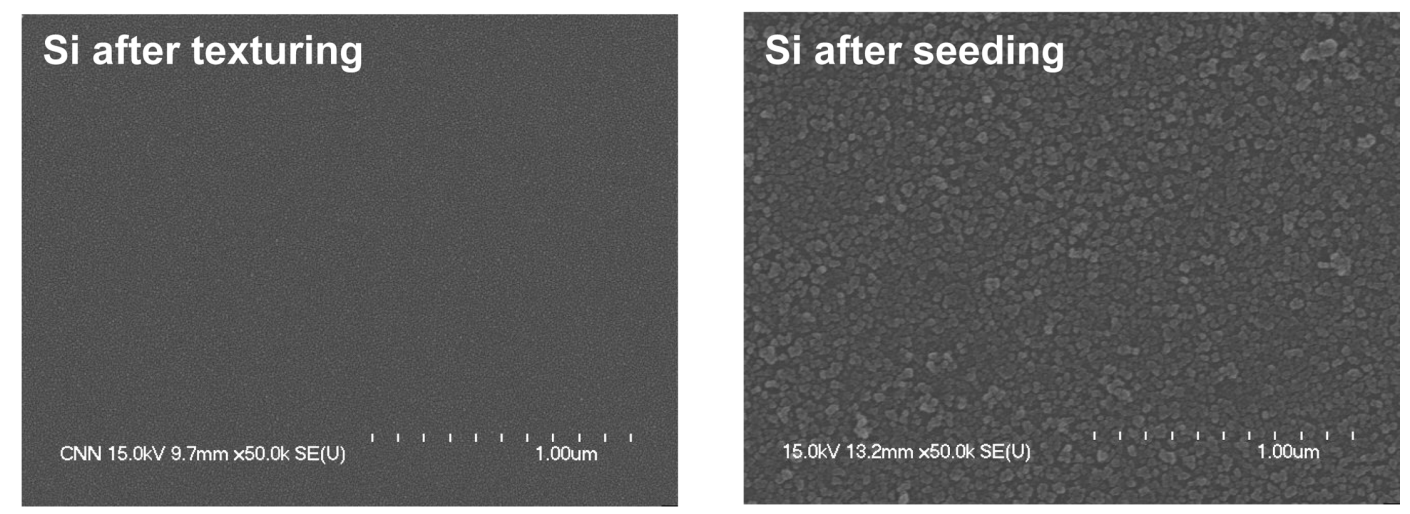

Fig. 7. SEM micrographs of the textured Si surfaces (a) before seeding and (b) after seeding. 
면은 상대적으로 높은 식각 속도와 제한적인 표면 조도 선택도를 나타내었다. 가스 총유량과 인가 power를 낮춘 $18 \mathrm{SF}_{6} / 9 \mathrm{O}_{2}$ 플라즈마에서(400 W source power, $100 \mathrm{~W} \mathrm{rf}$ chuck power) 압력을 변화시키면서 texturing한 $\mathrm{Si}$ 표면 은 더 낮은 영역의 식각 속도와 2 16 범위의 매우 넓은 영역의 정규화된 조도 선택도를 제공함을 확인하였다. $18 \mathrm{SF}_{6} / 9 \mathrm{O}_{2}(400 \mathrm{~W}$ source power, $100 \mathrm{~W}$ rf chuck power, 10 mTorr) 플라즈마를 이용하여 표면을 texturing하고, 나노결정질 다이아몬드 입자 분산액 중에서 seeding한 $\mathrm{Si}$ 기판은 $\sim 6.5 \times 10^{10} \mathrm{~cm}^{-2}$ 의 매우 높은 핵형성 밀도를 나타내었다. 또한, seeding된 나노 다이아몬드 입자들이 전 표면 영역에 걸쳐 균일하게 분포하고 있어서 $\mathrm{SF}_{6} / \mathrm{O}_{2}$ 플라즈마 texturing이 $\mathrm{Si}$ 표면으로부터 높은 나노 다이아 몬드 seeding 효율을 확보하는데 매우 효과적인 전처리 공정임을 확인하였다.

\section{감사의 글}

이 논문은 2012년도 정부(교육과학기술부)의 재원으로 한국연구재단의 지원을 받아 수행된 연구임(원자력연구기 반확충사업 전략기초연구, No. 2012M2B2A9A02030016).

\section{참 고 문 헌}

[ 1 ] O.A. Williams, M. Nesladek, M. Daenen, S. Michaelson, A. Hoffman, E. Osawa, K. Haenen and R.B. Jackman, "Growth, electronic properties and applications of nanodiamond", Diamond Relat. Mater. 17 (2008) 1080.

[2] J.E. Dahl, S.G. Liu and R.M.K. Carlson, "Isolation and structure of higher diamondoids, nanometer-sized diamond molecules", Science 299 (2003) 96.
[ 3 ] K. Panda, N. Kumar, B.K. Panigrahi, S.R. Polaki, B. Sundaravel, S. Dash, A.K. Tyagi and I.-N. Lin, "Tribological properties of $\mathrm{N}^{+}$ion implanted ultrananocrystalline diamond films", Tribology International 57 (2013) 124.

[4] H.A. Girard, J.C. Arnault, S. Perruchas, S. Saada, T. Gacoin, J.-P. Boilot and P. Bergonzo, "Hydrogenation of nanodiamonds using MPCVD: A new route toward organic functionalization", Diamond Relat. Mater. 19 (2010) 1117.

[ 5 ] A.V. Sumant, O. Auciello, R.W. Carpick, S. Srinivasan and J.E. Butler, "Ultrananocrystalline and nanocrystalline diamond thin films for MEMS/NEMS applications", MRS Bull. 35 (2010) 281.

[6] K. Panda, N. Kumar, B.K. Panigrahi, S. Dash, H.-C. chen, I.-N. Lin, N.-H. Tai and A.K. Tyagi, "Tribological properties of ultrananocrystalline diamond and diamond nanorod films", Surf. Coat. Technol. 207 (2012) 535 .

[7] O.A. Williams, O. Douheret, M. Daenen, K. Haenen, E. Osawa and M. Takahashi, "Enhanced diamond nucleation on monodispersed nanocrystalline diamond", Chem. Phys. Lett. 445 (2007) 255.

[ 8 ] P. Ascarelli and S. Fontana, "Dissimilar grit-size dependence of the diamond nucleation density on substrate surface pretreatments", Appl. Surf. Sci. 64 (1993) 307.

[9] S.D. Wolter, J.T. Glass and B.R. Stoner, "Bias induced diamond nucleation studies on refractory metal substrates", J. Appl. Phys. 77 (1995) 5119.

[10] T. Tachibana, Y. Yokota, K. Hayashi, K. Miyata, K. Kobashi and Y. Shintani, "Parametric study of biasenhanced nucleation of diamond on platinum in microwave plasma", Diamond Relat. Mater. 9 (2000) 251.

[11] E. Wörner, "Low-pressure synthetic diamond", Eds. B. Dischler and C. Wild (Springer, Berlin, 1998) p. 165.

[12] J.K. Kim, S.C. Ryu and H. Cho, "Diamond thin film deposition on Ni in microwave plasma CVD", J. Kor. Crystal Growth and Crystal Technol. 6 (2002) 311.

[13] H. Cho and J.K. Kim, "Parametric study of diamond/Ti thin film deposition in microwave plasma CVD", J. Kor. Crystal Growth and Crystal Technol. 15 (2005) 10. 